\title{
(A4. ALTERINATE
}

PLATFORM

\section{Youth Month - Reimaging Tomorrow: Our Turn. Our Time. Our Future}

Itumeleng Tyantsi

\section{June 16}

This is the day when more than 20000 pupils from Soweto began to protest. It is known as the Soweto Uprising of 1976. It is a holiday dedicated to the youth of our country. The youth from Soweto on this day decided to protest Bantu Education and the use of the Afrikaans language as a medium of instruction in certain schools. This event resulted in the deaths of youths around Soweto, including the iconic Hector Pieterson who died as a young boy shot by the police. This day is celebrated across South Africa to honour the courageous students who fought against Afrikaans as the only medium of language for education.

\section{Our turn}

So, they call us the 'broken generation', the lost souls, the not so 'smart' generation. But then again, we are the youth of today. Look at the definition of youth: 'a time in life when one is young, between childhood and adulthood" or appearance, freshness and vigour. My point is that does it matter that much that we became the same as our parents or our grandparents? It really should not be a problem if we are enjoying our youth differently from them. It would never make sense to be called a youth when you do not show or represent any freshness in comparison to those older than you. \#LetTheYouthBe!

Let the youth enjoy themselves, make changes and cherish their youth days. We will not get them back. The youth of today is different from the previous youths, they do things differently, socialise by rather using social media platforms to communicate, raise awareness about things they do not like; they are stepping outside of the box to make sure 
they reach one another and instil knowledge in each other. That is how unique and different the youth of today is from the other youths. We make use of our turn to showcase our talents, capabilities and our intelligence. It is our turn to be youthful and represent the nation. \#YouthMonth. \#PrideMonth

\section{Our time \#KeNakoYaRena}

It is time for us Youth to take a stand and never crumble down as this world is a tough one. Make decisions that are suitable for you. Let us follow in the footsteps of the youth that fought for us to be independent and made sure we can learn in the way we desire. Let us take a stand and fight for our dreams, conquer every obstacle in our way. Let us create new ways for the coming generations, make choices so that when we look back, we will be proud of it. Let us use this time wisely and effectively, as the saying 'time lost is never regained' is very true. Play as much as you want, have fun and go out, but always remember and put your goals first and never mess or play with them.

\section{Our future}

The future is in our hands-stop trembling, otherwise, you will drop it down the drain. Use the time you have that is now and start creating a better future. Just like the topic 'Our Turn. Our Time. Our Future., use your time to make proper decisions that will secure your future. The world is not going to be soft with you because you are relaxed. It is still going to be hard and the harder is, the more you need to make firm decisions. As the youth, we need to strive and make tough decisions that will ensure that our future is secured and well planned. Take drastic steps that will safeguard our future. Let us explore the world, change things in the nation and never forget where we come from. Your future as a youth depends on you and how well you use your time and focus on your goals. Never let the world let you think that you are not capable of securing your future or making your dreams come true. You are truly a South African child that will achieve anything and everything only if you believe in yourself. We will overcome many obstacles as the youth, and we will keep on overcoming many hurdles and prosper as we should. Never let your dreams fade and stop trying to achieve them.

\section{\#FollowYourDreams\#BeYourselfAndFightForYourDreams}

\section{\#TheFuturelsYouthDay}

Amandla Awethu 